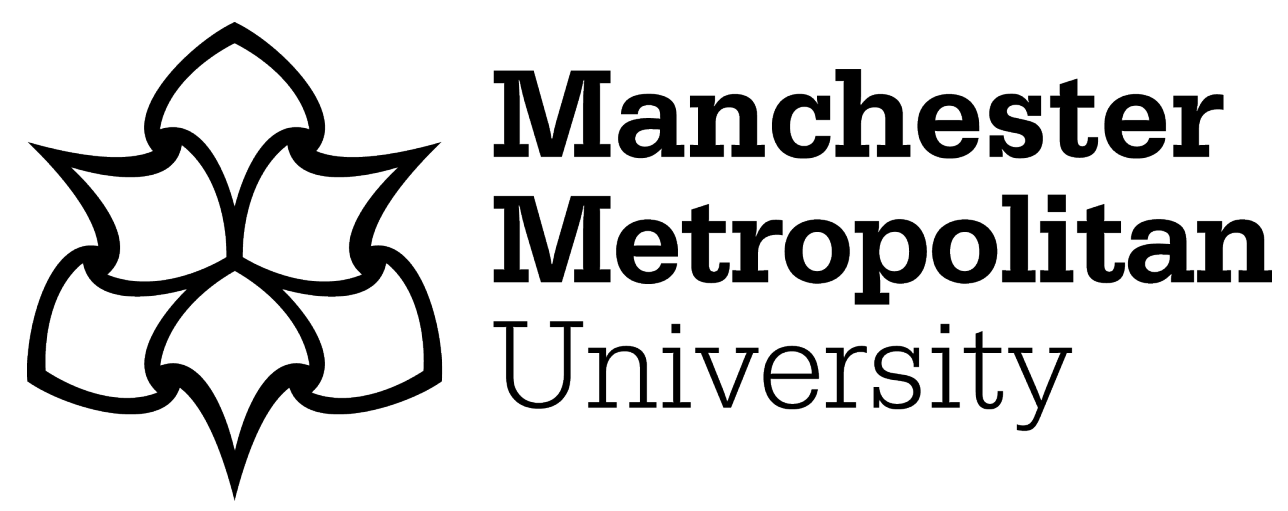

Peirson-Smith, Anne and Peirson-Smith, Ben (2021) Fashion archive fervour: the critical role of fashion archives in preserving, curating, and narrating fashion. Archives and Records, 41 (3). pp. 274-298. ISSN 2325-7962

Downloaded from: https://e-space.mmu.ac.uk/628371/

Version: Accepted Version

Publisher: Taylor \& Francis

DOI: https://doi.org/10.1080/23257962.2020.1813556

Usage rights: Creative Commons: Attribution-Noncommercial 4.0

Please cite the published version 


\title{
Fashion Archive Fervour: The Critical Role of Fashion Archives in Preserving, Curating and Narrating Fashion
}

\author{
Archives and Records, Special Issue on Archiving Popular Culture
}

\begin{abstract}
Fashion items and artefacts across the 19th and 20th centuries were once considered unworthy of placement in museums and archives on account of their perishable nature and their association with the shallow pleasures of low culture. The perceived fragile and ephemeral nature of fashion garments and accessories has been re-evaluated with material objects now considered worth saving for multiple purposes and uses. Awareness of the high social, cultural, economic and historic value of physical fashion relics has resulted in the trend for fashion designers, brands and museums to collate, create and manage fashion archives. The article analyses the importance for both industry and consumer of preserving and accessing fashion archives in the 21 st century in both digital and traditional ways. It highlights the benefits of collating a holistic multi-modal archive by combining material and textual cultural objects in various forms to portray and contextualize the lived social experience. A case study will analyse a selected educational fashion archive based in postcolonial Hong Kong. The contemporary fashion archive's role is evaluated from the perspective of archivist and user regarding contested issues such as commercialization, curatorial objectivity or controlled access, while evaluating future directions for the fashion archive as ultimate style repository.
\end{abstract}

Keywords: fashion archives, material culture, fashion collections, postcolonial identities, Hong Kong.

\section{Introduction}

The presence of fashion related records in the archive, as with fashion collections in the museum, ${ }^{1}$ has provoked critical debates across the past five decades about their respective function, purpose, validity, management, application and use from a formalist versus a modernist or postmodernist viewpoint. On the one hand, while fashion scholars acknowledge the place of fashion collections in museums and archives, and costume and textile collections have been a staple part in many global museum collections of categorised apparel across time, the "competing demands of fashion delivered in the academy, the marketplace and the museum" ensure that there are many positions about the way that fashion is represented, as with other forms of material culture. The reasons for the ways that fashion has been preserved and presented in museum collections is at stake here and the dichotomy between the perception of fashion as a fleeting condition in its defining principles being seen as of the current moment or the vogue "a desired mode 
of behaviour or appearance and a sense of successive change, movement and redefinition", 3 , which contrasts markedly with the notion of museum, library or archive as long-lasting, permanent structures marking longitudinal occurrences. This contradiction can be challenged on the basis that the significance of fashion for archives transcends the passing fads of the fashion cycle and is a barometer of collective social values and cultural expression given that "fashions are the property of larger or more representative groups." Moreover, fashion is the way that individuals across time, space and place consistently use or technologize the site of the body to communicate and perform identity, belonging and difference. ${ }^{5}$ Some critics adhere to a traditional focus on the importance of the material object as departure for the presentation and representation of fashion as a significant historical process founded on critical evidence as provenance ${ }^{6}$ of how garments are made and worn. While others, taking a more postmodern Foucauldian approach, promote the notion that fashion in museums and archives in the $21^{\text {st }}$ century are a user-focussed experience often disconnected from historical prescriptions or concerns ${ }^{7}$ that are constantly evolving regarding their interpretation and ownership. Other scholars suggest that fashion should be represented within the context of the production and consumption systems above pure concerns with aesthetics, culture, economy or the elite and romanticised glorification of the individual designer, given that the industry involves the collective efforts of a range of cultural intermediaries in enabling a garment to be produced, created, promoted and delivered at point of sale across the globalised supply chain. ${ }^{8}$ Beyond this point, some argue for the role of fashion and archives in contextualising the narrative of fashion texts, ${ }^{9}$ while others highlight the vital role that fashion archives play in scholarship ${ }^{10}$ and design education.

At the heart of these debates about fashion museology and archive practice also lies a contested understanding of why fashion items are worthy of preservation and what 
items are considered to be worthy of inclusion in archival records and collections and how regarding their administration in the selection and preservation process, their management by archivists and ultimately in their access and end use by varied stakeholders with an interest in accessing and contributing to archival content. This article explores the dynamic and shifting role of fashion archives and the associated role of collection-based fashion archives, highlighting the debate underlying the nature, value and usage of records that typically constitute the focus of archival practice thereby impacting on the contingent roles of creator, archivist and user. It first examines the contested debates surrounding the evolving role of fashion archives, archivists and users across time in relation to considerations of evidence (encompassing record and event), ownership, memory, identity and community. The term 'archive' in the current context will be interpreted here more broadly in a postmodern sense ${ }^{11}$ as encompassing a wide variety of mediums including material objects, records and digital texts invested with continuing or enduring value ${ }^{12}$ for a given society in some perceived form, simultaneously transforming past, present and future ${ }^{13}$.

This exploration will further identify the notions of archival value, nature and use in a grounded case of a special archive collection attached to an educational institution in a specific geographic location where archival practices today are largely still evolving. The essay assesses the practical manifestation of these debates about the nature and purpose of archive collections, creators, archivists and users and their interaction with, and contribution to communities of practice, such as fashion and design education. It aims to determine whether the custodians and stakeholders involved in fashion archives, related records and special collections represent a distinctive occupational community with unique features and requirements, and addresses related questions about the ways "art and popular culture use materiality to bring the past into the present in the service of 
the future" at the same time as "memory objects [are] inscribed with meaning, affect and agency." 14 As an overarching concern, the role of contemporaneous fashion archives in representing identity narratives is examined, given that fashion archives are located in various geographic locations signifying different cultural and national narratives. By extension, the paper will address the management of non-essentialist world fashion stories that offer an alternative to Euro-centric and ethnocentric views of the evolving fashion system in local contexts.

The conceptual framework maps the unifying principles driving archives on the one hand, and the different purposes and requirements that might need to be accommodated for various creators and users on the other, taking into consideration the specific and emerging cultural context and its complexities within which the modern archive is situated. Finally, based on a grounded case study, the article will critically evaluate the fashion archive's role from the perspective of archivist and user. In doing so, it will address associated contested issues, such as commercialization, curatorial objectivity or controlled access in colonial and postcolonial ${ }^{15}$ contexts, while evaluating future directions for the digital fashion archive as ultimate style repository.

\section{Fashion Archive Fervour}

Fashion items and artefacts were once considered unworthy of placement in museums and archives across the $19^{\text {th }}$ and $20^{\text {th }}$ centuries on account of their perishable nature or material impermanence, in addition to their association with shallow pleasures, gendered female interests and the pursuit of low culture. ${ }^{16}$ Even within the field of archive theory, debates still rage about the validity and worthiness of some archive content over others in adhering to the "canon" with some interpretations of heritage having dubious validity or value given that:

mass media consumers share extensive repertoires in sports, music, fashion, 
and popular culture. But that store of data is trivial, inchoate, and ephemeral; it nourishes no discourse beyond its own short-lived icons; it links its devotees with only a very recent past; its substance is too thin to support a meaningful social fabric. ${ }^{17}$

The notion of fashion as an inferior endeavour, both in its production and consumption processes and practices, has assumed various forms in institutional contexts (e.g., museums), and in educational curricula, on account of its perceived base associations with the textile industry, commercial enterprise or purely womens' concerns and therefore less important, given that fashion courses was often located in Home Economics Departments of North American Institutions ${ }^{18}$, for example. Steele explains that "fashion seemed "unworthy" of entering the museum. Even as an example of the decorative (or applied) arts, fashionable dress was apparently inferior to tapestry, furniture, or ceramics. ${ }^{19}$

The marginalisation of fashion as a phenomenon worthy of collection, preservation, or serious study is also rooted in the $19^{\text {th }}$ century moralistic separation between work and leisure, higher and lower pleasures,${ }^{20}$ cognitive creative outputs and worthy products of 'human endeavour' appearing to be at odds with the degrading physical pleasures of the body. For critics of the day, fashion resided at the intersection of both sublime achievements and base pleasures, intimately connected with the embodied human form and its related ability to heighten desire and evoke emotions. At the same time, fashion also represents the barometer of social taste, status and attainment based on the affordability of luxury textiles and tailored outfits, which in turn resulted from the outputs of creative labour and crafted design talent emanating from the creative industry sectors. 
Representation of fashion in museums was consequently guided from the outset by an object-based dress or costume history tradition and scholarship. Yet, the latter field is often criticised for its separation from vital cultural or socio-economic contexts and considerations. ${ }^{21}$ The postmodern turn in cultural production, as with managing archives, over the last few decades has signalled recognition of fashion's significant contribution to social and cultural history and its role in identity formation, ${ }^{22}$ in validating "the fashioned body as a site for serious cultural analysis. ${ }^{, 23}$ This critical approach challenges the role of fashion and related cultural industries as being mere forms of entertainment or in representing the dubious output of popular 'low' culture. ${ }^{24}$ The more critical approach to the role of fashion in culture and society and its representation within cultural institutions has also been informed by cultural studies scholarship and its focus on language and representations of identity geared to producing scholarship "to live by the word". ${ }^{25}$ By way of contrast, the garment as object is still often marginalised in museums where not all artefacts are seen as having equal status, and are often downgraded in favour of content considered to have more knowledge capital. Hence, Steele explains that:

[...] many people believe that only some objects, such as works of art, are worthy of being conserved in a museum. Old clothes would seem too trivial and ephemeral to save... Books, after all, represent the accumulated wisdom of the ages, while the fashions of the past are often regarded as a monument to the vanity and defective taste of our ancestors. ${ }^{26}$

Some scholars and curators have lately championed the need to preserve objectbased research as an essential part of fashion historiography. ${ }^{27}$ Blended with interdisciplinary approaches from consumption studies and material culture analysis, they yield a more nuanced socio-cultural or socio-economic understanding of the visual and heritage aspects of fashion, often relying on extensive archival research for their core 
methodology that merges with wider interdisciplinary research approaches. A blending of the two stances - seeing fashion both as object focused and as being usefully represented in archival texts with opportunities for decoding the social and cultural meaning of objects and texts - appears to offer a more balanced and contextualised approach. This enables the telling of fashion stories by educators, students, designers and fashion communications professionals based on multi-vocal archival materials. It is an approach rightfully acknowledging that typical archival materials such as sketches, photographs, letters, and print-based advertising are all material objects too, having as much physical form as a jacket, dress or hat, and offering the ability to contextualise fashion object or theme in conjunction with dress as object. As Anderson explains:

The use of representations and a focus on garments as objects need not be contradictory, but can in fact be produced by a designer like Calvin Klein alongside one of his advertisements gives a much more thought-provoking context to his work than of the garments when displayed by themselves. It also provides opportunities to relate to the wider public's daily experience of highlevel designer fashion, which is mostly through images rather than the garments themselves. $^{28}$

As a consequence, fashion designers, educators and researchers can conceptualise and execute design briefs by transcending the physical garment and contextualising their designed collections to reflect "external intellectual, commercial and educational developments". ${ }^{29}$ In this sense, all forms of physical object have the potential to operate as important artefacts with multiple applications, enabling users to further their understanding of the contextualised garment, accessory or fashion advertisement and its creative inspirations and application. This approach changed how archivists' and curators' viewed and managed their collections, recognising that fashion as object and 
text is a nuanced part of embodied, daily experience potentially representing barometers of social and cultural change ${ }^{30}$ in the process of developing theory from the fashion object and record or vice versa. Hall suggests that:

Clothes are historical documents. We imbue them with our personal histories and identities, and they thereby contain a depth of personal, transient narrative that can be easily lost to history. The details of the era, such as advertisements and pamphlets, or even dresses, gloves, hats and coats, can provide valuable cultural evidence to historians working in the arts, enriching the understanding of a particular period, providing new insights or interpretations, and inspiring new forms of creative outputs. It is the work of fashion archives to collect, curate and preserve this history. ${ }^{31}$

\section{Archive Fervour}

The academic study of the relationship between fashion and archives itself is still in its infancy, unlike the scholarly evaluation of the relationship between fashion and the museum, which has been a more active subject of debate across the past decade. The close relationship between museums and archives is reflected in their management and can be viewed as repositories of collections that are preserved and curated for selective display and in allowing access to a range of stakeholders and publics for a variety of purposes from personal interest to academic research.

The relationship between fashion and archives is also premised on perceptions of the functional and philosophical form in terms of the value and usage of records comprising the archive itself, founded on a contested dichotomy between the role and management of evidence and memory in archival discourse. ${ }^{32}$ This "archival nexus", as it has been termed, has fuelled theory and debates about archival practice in terms of the rationale for archives, and the related role of archivists, surrounding their creation, 
management, purpose, role and utility. The debate has further extended around the supposedly competing human interest in the formation, transmission and usage of the archive and its contents by record creator or record user, and the power relations that underpin this complex, hegemonic dynamic.

From a customary professional perspective, as Cook observes, “Archives have traditionally been about acquiring, describing, and preserving documents as evidence, preserving their impartiality through the archivist's self-conscious stance of neutrality and objectivity". ${ }^{33}$ Accordingly, archivists as record selectors, choosing what is preserved, thereby become creators or guardians of records. In this role they preserve the value of records based on evidence and the substantiation of factual scenarios, despite the absence of the role of the user. ${ }^{34}$ Conversely, more contemporary, 'postmodern' considerations $^{35}$ have highlighted the significant role of the record user as being critical in foregrounding archival concepts of historical importance in a more subjective, interpretive way recognising that archives are constituted of public place and private space $^{36}$ that is managed privately yet publicly accessible. This approach foregrounds the vital role of archives for deeper understanding of culture, heritage and memory ${ }^{37}$, which largely accounts for the varied needs of the end user and the importance of more open and adaptive user-facing dissemination strategies and situated community engagement with their content or records, ranging from community members donating clothing of interest and their back stories for local collections or exhibitions to crowd-funded online publications or open access digital fashion archives such as Europeana's Fashion collection or Google's "We Wear Culture" fashion archive. Records have been described as any 'piece of information that has been captured in some fixed medium. ${ }^{38}$ Most modern definitions, such as those by Caroline Williams, find that this 'information [was] generated by organisations or individuals during daily business and personal 
transactions ${ }^{39}$ by conveying documentary value of something happening that can be relied upon as evidence of a significant occurrence. Archives form a subset of records determined to have continuing or enduring value for a given society in some perceived form. Therefore, archives, like records, can come in a variety of mediums, from 'handwritten diaries to typed letters or word-processed reports' ${ }^{40}$ to a whole panoply of material objects and records. Hence, the fashion collection and archive can act as form of material palimpsest of 'memories and traditions" ${ }^{41}$ or a composite of fashion-based materials, accessories, objects, texts and images as the Westminster Menswear archive ${ }^{42}$, the Yorkshire Fashion Archive ${ }^{43}$ or Fashion Institute of Technology collection (FIT) in New York ${ }^{44}$ all exemplify. This contemporary understanding of archives broadens the scope of what can be classified as constituting an archive moving away from the traditional 'fonds' notion of managing a purely records-based repository to encompass an understanding of the need to account for past occurrences connecting with a range of multi-modal sources existing in private and public spaces. Some commentators consider the notion of the archive to be limitless and boundless whereby any site, including the body or a dance performance can activate the "archival impulse" using past events or objects enabling the activation of affect and memory for the audience where the dancer's body, for example, can be archivist and archive in creating and enacting transformative moments in time ${ }^{45}$. This perspective has clear parallels with the use of the clothed body and its environs to shape and perform constructed social, cultural, aesthetic and political discourses. Contemporary fashion archives can comprise a multifarious collection of physical textiles, garments, accessories, photographs, print and broadcast advertising in addition to digital records of these items and other fashion moments ensuring more transactional engagement. 


\section{Mapping Fashion Archives}

The last two decades have witnessed a complete rethinking of the management of archives and records from a total concern with their impartiality and authenticity, Records and archives now occupy a 'boundary spanning' role requiring archivists to be proactive, active and reactive in consideration of the type and purpose of records collected and in terms of their evidential capacity and the needs of communities and societies they endeavour to serve by encompassing and accommodating historical, cultural, heritage and memory-based values. Archives, according to this multi-functional "total" perspective, can be used for unlimited purposes by any number of infinite users. Therefore, if archives can be interpreted in an infinite number of ways, they can be seen to have an infinite potential number of uses and archive preservation and usage will evolve and change alongside new interpretations of their value.

Equally archivists as arbiters or 'mediators' in their role as both creator and user and working with, and on behalf of various stakeholders are increasingly more visible ${ }^{46}$ and actively involved in selecting records from the point of their creation onwards, while working with record creators to identify documents worthy of preserving to ensure inclusivity and added social value on behalf of a wide pool of interest. By extension, the role of the archive and archivist in specific communities and communities of practice ${ }^{47}$ has emerged from its judicial legacy role to the representing the source of cultural memory and from societal engagement to community archiving. This shift in archival role and practice has transformed the role of archivist "from passive curator, to active appraiser to societal mediator to community facilitator" 48 from passive custodian to active interpreter.

The role of the archivist is arguably centrally concerned with two main concepts; preservation, the activity ensuring archives collections are preserved for the future; and 
access, guaranteeing that users have access and can utilise them. To deliver an effective service safeguarding on-going access to collections, archivists are encouraged to understand the identity and needs of users, while providing adequate information to users about services and holdings. This approach could be developed upon a knowledge of existing audiences in order to ensure that collections have relevant social reach and are able to secure funding ensuring the sustainability of services provided with high standards of service delivery ensured, in part, through compliance with access standards. The needs of the users of fashion as a community of practice will be examined next to determine if it requires special treatment or shares commonalities with other archives. In practice, the nature of fashion archives appears context-specific and these archives loosely fall into the following categories: corporate fashion archives; heritage archives, academic fashion archives; digital online archives. The relatively new interest in creating fashion archives constitutes 'records of a number of varied fashion products ranging from garments to company marketing materials. ${ }^{49}$ Their value resides in the established need for primary sources to provide evidence for creative inspiration and preserve memory for a range of users representing social value, cultural value, collective memory, education value or national and local identity. Given the specific requirements of fashion as a specific community of practice in the creative industries, ${ }^{50}$ evidence in material, documentary and digital form is required to inform design practice and fashion branding. 51

Equally, memory of aesthetic and technique operates as a source of creative inspiration for fashion professionals working across the value chain from design to marketing enable users to examine, evaluate, interpret and construct new designs, influencing fashion trends or in approaching new ways of telling a fashion brand story or a national fashion story. Hong Kong's global fashion city aspirations are based on its 
transformative evolution from textile and garment manufacturing-based production hub to a service-oriented economy via the discovery and use of design technology and the promotion of local Hong Kong fashion design brands by the Trade Development Council (TDC). Equally, Hong Kong's journey from making to creating and designing with the push to export Hong Kong produced fashion brands internationally at commercial fashion trade fairs and fashion weeks, ${ }^{52}$ including holding a bi-annual Fashion Week event from the late 1960s. The hosting and reportage of promotional fashion events, in addition to the setting up of tertiary level fashion design education programmes from the 1980s, highlights the aspiration to be recognised as a creative design centre ${ }^{53}$ mirrored by the slogan 'Made by Hong Kong' rather than as a 'Made in Hong Kong' manufacturing base locating its place on the global fashion design map. ${ }^{54}$ There are no comprehensive fashion archives in Hong Kong and fashion related content tends to exist as supplementary content for museum collections as with the Bruce Lee: Kung Fu • Art • Life exhibition showcasing Bruce Lee's iconic track suit and martial arts outfits in the exhibition 2013-2020 at the Hong Kong Heritage Museum in Shatin; or with fashion archives as a niche teaching resource in higher educational institutions such as the Institute of Textiles and Clothing, the Fashion \& Textiles Resource Centre at the Hong Kong Polytechnic University. Other general archives exist that could be of contextual use for the fashion scholar or for teaching purposes, such as The Public Records Office, The Hong Kong Film Archive, The Hong Kong Heritage Project or the Kadoorie Archive, yet none of these examples fully focus on fashion as content. The reason for this relatively piecemeal approach to fashion archives may reside in the generic marginalisation of fashion as a core content subject worthy of study. Beyond this, Hong Kong archives in general have never been regulated by legislation in terms of the retention or disposal of records, either under 150 years of British colonial or post-handover in 1997 to 
date ${ }^{55}$ suggesting an ideological colonial or postcolonial devaluation of records management, consciously or otherwise.

The next section provides a case study of the Hong Kong Design Institute (HKDI) fashion archives, set up to serve the needs of an educational institution as a learning and a community resource, using the four-part paradigm or framework to structure an analysis of the archival mindset given that "evidence is not memory and community. ${ }^{56}$ The analysis is based on an observational visit by the authors and an onsite interview with the head curator/archivist and team to make sense of the purpose, scope and application of the archive by focusing on its purpose regarding evidence, memory, identity and community from the perspective of archivist and user.

\section{Archive Case Study: Hong Kong Design Institute (HKDI)}

The Fashion Archive (FA) resides in the newly designed and renovated Hong Kong Design Institute (HKDI) Tseung Kwan O campus, a tertiary institution in the Special Administrative Region of Hong Kong, offering a range of design-based courses as 'a dedicated and committed institution pursuing excellence in fashion design education and research and taking a leading role in fashion education in the region ${ }^{57}$ (Figure 1). This government-funded archive is a designated centre of research excellence, part of the Department of Fashion and Image Design, housing 1,500 historical fashion items in a dedicated 360 square metre space (Figure 2). In addition, it offers an interactive platform of the fashion collection available online (Figure 3) aiming to serve its institutional constituents and a wider public 'with a view to attracting thousands of visitors every year. ${ }^{58}$ The FA website explains its mission to be to become the backbone of a 'Fashion and Consumer Culture Research Centre', where real fashion products are used as teaching and learning tools in fashion design education. Through the wide-ranging reallife fashion resources available and the application of modern interactive technology 
users will be provided with immersive experiences in aesthetic and analytical appreciation, linear historical evidence and understanding of garment forms and construction. $^{59}$

\section{Fashion Archives and Evidence}

The concept of evidence or the record-event dynamic is central to the founding rationale of archives across disciplines as the site underpinning where 'we as individuals, as communities, and as cultures and societies, perceive, conceive of, and make use of records ${ }^{60}$ based on events, actions, thoughts that produced them in order to make more sense of them than would otherwise be possible. ${ }^{61}$ The role of the FA and archivist at HKDI is guided by a clear brief of selecting, managing and making available evidence of fashion-related items, past events, oeuvres and times representing Hong Kong fashion. The notion of fashion objects and associated records as contextual historic evidence as a conceptual lens through which archival records are viewed, in terms of their type, value and usage, was evident in discussion with the archivist. A strong sense emerged of records being collected and preserved to contribute to the representation of events or series of events, in this case contextual fashion history relating to Hong Kong, for specific educational purposes. The curator explained that the move of collected items to a dedicated space on the new campus enabled the collection to evolve from closed to more open and available access for users. This transition enabled a new lease of life for 1000 objects and records that had previously been catalogued and held in storage and enabled access to objects and records for workshops and sharing sessions.

The traditional requirement to preserve the collection in the new archive in a systematic way resulted in the utilisation of conservation technology such as temperature controlled storage units or the use of acid free storage paper. Given the special 
requirement to conserve textiles and material culture this was a key priority, notably in a humid Asian climate or with heavy silver-inlaid ethnic dress.

Equally, the shift from being perceived as guardians of text-based evidence, to mediators of materials, that are multi-modal in format and multi-sourced in origin, represents recognition of the changing needs and roles of archive, archivists and users. Significantly, the FA is a relatively new initiative showing that many archives in the context of Hong Kong and Asia are in their infancy or often operate in a piecemeal way ${ }^{62}$ on account of the differences in cultural value systems and historical accounts constituting a contested site, given the subjective narratives attached to colonial heritage ${ }^{63}$ and the need for a new post-colonial or de-colonial identity politics "to liberate it from the reified colonial past (the so-called collective memory) and the commercialized future (more shopping malls)." ${ }^{64}$ In this context both archives and archives containing fashion are new and without precedent, providing both challenges and opportunities for emerging archives.

On the one hand, the fact that the fashion archive is a relatively new enterprise for Hong Kong has the potential to generate interest through the novelty effect and serves needs and users hitherto not catered for. Yet, at the same time it places pressure on the archivist to assume responsibility for preserving, appraising, managing and promoting the collection. It can also create pressures in terms of funding and support for exhibitions and outreach, as the archivist explained. This is still new for Hong Kong as funding or external sponsorship support from government departments such as CreateHongKong ${ }^{65}$ or external private sources such as textile or garment producers is often dependent on having a track record, which can be problematic for a new and developing archive and often necessitates the initial run of an exhibition being planned in a low cost resourceful way as proof of viability for future related events. 
The sense emerges here of managing a new initiative, while at the same time attempting to create a new mind-set about archive appreciation, based on demonstrable success when judged as only being good as the last project. For a new archive endeavour extra support is often hard to secure from government or industry because of lack of precedent or a proven track record in securing funding. This highlights how contextual and cultural considerations impinge on the existence and evolution of archives especially in a post-colonial context and the inherent sensitivities of using records and objects to frame the dominant political narrative. Preserving and managing records and objects to assist in making sense of this narrative are inevitably complex given the colonial and postcolonial experiences that Hong Kong has traversed in its history, and rarely reflected in the lack of legal or policy support for all of Hong Kong archives in general. More specifically, from a fashion perspective, colonialism is marked out through the material manufacture and flow of goods ${ }^{66}$ such as textiles and fashion objects often that are based on the labour of the colonised. Historically, Hong Kong's fashion story is rooted from the territory's 19th century heritage as a British colony operating as a trading centre for production, distribution and consumption across its empire which came to accommodate textile and garment production from mass manufacturing and ready to wear to a serviceoriented economy from the 1950s, allied to the invention and use of design technology and the promotion of local Hong Kong fashion design brands from the 1980s created by designers educated in Hong Kong fashion and design schools, who were desirous of world recognition and accessing global markets. ${ }^{67}$ The colonial Hong Kong government marketized the economy by establishing a laboratory of modernity encompassing a growing manufacturing worker base from a post-industrial, neo-liberalised educated workforce enabled by the territory's status as a flourishing trading hub and financial centre, and latterly as an aspiring creative fashion city and retail hub. Power relations 
inherent in this historical narrative reside in the objects and texts of popular cultural forms as located in the fashion sector, its workers and the material outputs of fashion items. The archive under discussion holds a range of items mapping this colonial and post colonial narrative with Qing Dynasty Chinese embroidered items or cheongsams representing the orientalist fascination of those collectors who donated them, while more modern pieces such as designer denim outfits from the 1980s and contemporary local designer outfits reflect the modernity that Hong Kong aspired towards and its imaginary East-West persona. As Craik observes, the collections of Hong Kong textile collectors "not only emphasise the historic specificity of these items but illustrate their contextual variability...not just demonstrations of customary dress but vivid examples of earlier Chinese fashion impulses." ${ }^{68}$ Material objects offer critical evidence in support of defining identities and representations of the colonised or subaltern, ${ }^{69}$ albeit being open to interpretation by users, highlighting the critical necessity of preserving and making this material-based knowledge available to accommodate multi-vocal historical narratives.

\section{Fashion Archives and Memory}

The negotiated role of the archivist as subjective appraiser of records and collections according to their historical value was also in evidence in this case, based on their responsibility for creation, evaluation, depiction and management. The nature and aim of the archive as an adjunct to an institution of higher education and a department of fashion design delineates its pedagogic role from the outset, as the archivist explained, 'The main goal for this centre or our mission is that we want to focus on teaching and learning for the benefit of our students.' In a new emerging archive, this flexibility appears to be essential in enabling evolution and development.

Notably, this is also a collaborative exercise incorporating various communities of practice working with the archivist. There is a small supporting team working with an 
external consultant, former fashion designer and curator, in addition to the Hong Kong Fashion Design Association (HKFDA), and teaching staff from the design programme. Collaboratively they source, advise, select or contribute relevant items for the archive. The use of collective subjective appraisal from support staff and subject specialist lecturers, albeit based on subject-based expertise, is apparent here in terms of sourcing and collating the archive content from a range of object based and documentary records sources including private and personal archives.

Notions of preserving and enhancing collective memory are a guiding principle for these exhibitions as the archive had planned to showcase some of its fashion collection, given that the foundational orientation was an educational one. Reflecting the colonial heritage of Hong Kong as a textile and garment manufacturer and the consequences of its prevailing postcolonial state as a global financial centre and trading hub, the collection comprises items largely from globally based or European designers, supplemented by local creations. This was exemplified by the archive's denim exhibition where ten pieces in one section were selected to showcase the use of the textile on the catwalk by high-end designers such as Jean Paul Gautier, for example, to highlight the diversified use of denim and to contrast it with the stereotypical view of denim as a contemporary street-wear staple. In this way, the globally sourced aspects of the archive serve to contextualise the fashion story for a local audience, while also validating the territory's connection with the world given its history as mid- $20^{\text {th }}$ century textile and garment manufacturer. Hence, the fashion archive can shape an understanding of Hong Kong's evolving fashion story from its colonial ties that connected it to the 'western' fashion system as one-time textile and garment workshop of the world to its modern postcolonial aspirations as a fashion capital, which remain in flux, despite policy rhetoric to the contrary, given the struggle that young designers encounter ${ }^{70}$ when trying to attain a 
global profile given the costs involved and the lack of contacts in the prevailing Eurocentric hierarchy ${ }^{71}$ of the fashion system. ${ }^{72}$ However, this perhaps is a changing story that the archive can recalibrate through its outreach projects and exhibitions that tell a more local and socially based narrative at street and community level.

\section{Fashion Archive Identity Issues}

The archive team appeared to represent a more postmodern, fluid interpretation of the identity of the archivist and the archive itself, given that none of the team had been trained specifically in archive work, but as subject experts in the field of fashion and design. They appeared to be well qualified for the job at hand based on their knowledge of textiles, fashion and design, in addition to the relevance of the content, growth and management of the collection in relation to their users.

There was a sense of the archivist's mediating role as boundary spanner between evidence and analysis, educator and archivist, in using specialist, academically trained knowledge competencies to make sense of the fashion items as a societal resource for stakeholders who want to elevate their learning by introducing new knowledge to upcoming generations. The archivist shared a story of including an image of Andy Warhol and the iconic Velvet Underground and Nico record sleeve that he designed in 1967 in the denim exhibition for contextualisation purposes. In discussing the exhibition, some of the students recognised the image from a previous Uniqlo t-shirt range, with some assuming that Warhol was a contemporary graphic designer. In creating the exhibition and narrating the story of denim in this case from selecting archive and constructing memory to communicating history that potentially transforms the manner in which younger generations understand design history.

The mediating and educative role of the archivist among creators, records and users, and the use of archives to traverse the past, present and future was evident in the 
accommodation for various levels of student user at different stages of their studies, and the opportunity to support content-based courses in fashion history by selecting items from the archive for illustrative purposes as a 'show and tell' exercise. The archivist exemplified this by explaining that on a contextual fashion history course the students visit the archive for a weekly lesson to handle selected replicas of garments such as Victorian dress or ethnic Chinese costumes, for example. The use of facsimiles of the original garments for teaching purpose perhaps echoes the traditional approaches to archiving in the preservation of original order. Yet, at the same time this exercise reflects the pedagogic value of fashion archives residing in contextualising the past by allowing students to gain sensory access to garments of the period under study so that students of material culture and design can feel and touch the items to determine how they are constructed and decode their fashion story in a three dimensional sensory manner (Figure 4). Also, this aligns with the approach of other fashion archives attached to other educational institutions in other countries where fashion archives are used for design teaching and practice ${ }^{73}$ and in preserving memory as well as actively creating it by encouraging use both inside the archive and in its online iteration by activating history. ${ }^{74}$

\section{Tailoring community outreach}

The holistic, "total archive" whose boundaries are more blurred, is perhaps the hallmark of the $21^{\text {st }}$ century archive. The ubiquity of the digital domain for information storage, management and retrieval has changed the nature of archives and the inherent power relations underlying the expertise and control of managing archival custodianship, in favour of a more collaborative engagement taking place in different contexts. Hence, archives such as the one under analysis are operating in both real and virtual domains and inside and outside the institution to which they are attached as a way of broadening their outreach efforts, in the interests of co-constructing civic memory. ${ }^{75}$ Taking inspiration 
from the Denim Days events in Amsterdam and New York, the FA, using a government grant from CreateHK, took a denim fashion exhibition, King of Fashion: Denim, into heritage building Police Married Quarters (PMQ) and the old garment district Sham Shui Po. ${ }^{76}$ (Figure 5) Both areas are part of a recent trend of gentrification of old neighbourhoods and buildings rezoned into cultural or retail spaces. Other commentators regard this as the urgent need to develop a critical discourse on Hong Kong architecture and urban space, where 'the dominance of visuality is put into question. ${ }^{77}$ The symbiotic uses of historic buildings and districts to showcase vintage garments alongside the new work of artists and designers using a themed or upcycled fabric, in addition to vintage denim collectors clearly operates as a platform to re-create an identity for both based on re-imagined memories and re-imagined communities ${ }^{78}$ in the hope of elevating a sense of community itself, arguably based on the communal acceptance of 'blatant discontinuities as continuities. ${ }^{79}$ In the postcolonial setting of Hong Kong districts and their inhabitants and workers, once part of the drive for economic marketization, are being re-zoned, redefined and gentrified as retail or heritage sites as a form of (dis)continuity with the past where traditional buildings reside alongside new structures as displays of urban modernity and evidencing "the disjunctures of colonialism and globalism." 80

Taking selected and themed archival objects and texts into these communities enables the re-working and the original historical use of these places and spaces in favour of a post-modern neo-liberal narrative equating Hong Kong as a creative city thereby contributing to broader economic development opportunities located in the rhetoric of place-making by governments and policy makers.

From the pragmatic perspective, taking an archive-based initiative into heritage buildings and areas intends to widen the numbers and type of users, while also activating and performing cultural memory in situ. Objects serve as stimuli to various responses and 
recollections, physically re-creating aspects of a time gone by; evoking a personal memory, forming records as 'analogues to living memory, storing information beyond individual experience. ${ }^{81}$ Here the social value of fashion objects resides not necessarily in the things themselves, but in their ability to act as a sensory and sensual triggers, communicating, mediating and evoking a range of responses by fulfilling different cultural and social functions in terms of community outreach. This endeavour attempts to raise awareness of heritage stories and encourages a sense of identity for residents and an immersive, learning experience for the visitor as a form of soft power. Equally, contextualizing the content of the event with value-added workshops, expert talks, international artists and items from other international archives, including the Levi's archive in San Francisco providing Steve Jobs' jeans, gives endorsement and lends interest that validates the multifarious roles of the archive for different communities of interest. Collaborative partnerships with fashion industry representatives, in this case Levi's or G-Star, were also a useful strategy to assure endorsement and attain various levels of support or capital, be it monetary, knowledge or assistance in kind or corporate support such as events management or the printing of promotional collaterals.

Also, to combat the notion of archives and museums being 'a cemetery for "dead" clothes ${ }^{92}$ given that clothing is 'part of our living, moving selves ${ }^{\prime 83}$ the community outreach initiatives attempt to bring the archive and its collection to life as a mobile, interactive entity at street level. To this end, the archive organised a well-attended Sunday denim market in the old fabric district of Sham Shui Po over two weekends aided by staff and students, complete with denim inspired craft stalls, a mobile truck contain a history of denim display, street-level fashion shows, indigo dyeing and denim design workshops, local music performances and artists offering individual portraits. 
This highlights the multi-usage of an archive in accommodating both its core and outreach efforts within the dynamics of urban space and place, as one exhibition based on selected pieces from an archive collection can be used or framed in different ways each relevant to situation and varying user interests given the universality of a material such as denim and its ubiquity in most people's lives. Hence, the denim exhibition after its City Road show returned to the FA for several months to serve its student population and become part of educational activities embedded in the curriculum (Figure 6).

The digital domain and its technologies have increasingly enabled the creation of a more holistic archive that can reach and cater to multiple stakeholder interests, from students and teaching staff to the wider public. This democratisation of the archive space and place also enables the preservation, presentation and conceptualisation of fashion as material object alongside other materials in print format such as photographs and magazines. The institution welcomed the value of open access and engagement in promoting its presence and stimulating usage through a wider user base, while also generating supporters and potential sponsors for the future. The archivist was initially sceptical of the value of adding a digital dimension to the archive reflecting and acknowledging the tension that exists between preserving and privileging the vulnerable fashion object, yet making it available, the archivist emphasised the need and value of digitising fashion archives for educational purposes in catering for a new generation more comfortable with accessing knowledge online than physically visiting a museum of library. Equally, the ability to facilitate 3-D engagement with a fashion garment is afforded by the advent and use of more recent technology, such as the virtual capacity to interact with garments in the collection to enhance garment preservation and making the collection more discoverable, while widening access for various users with varied needs as the archivist explained. 


\section{Conclusion: Fashioning Adaptive Archives}

The unifying theme emerging from this analysis of fashion archives is one of change and adaptation, not only of the content of records and collections, but of how they are managed, curated and preserved, who they are made available for, how that access is facilitated, and how and why they are accessed and used. Added to this is the notion of permanence and impermanence - with fashion being misperceived as having a temporary existence, yet its lasting physical form imparts knowledge and evokes memory, generating a sense of community and place. Additionally, while many themed events and exhibitions organised by archives and institutions based on selected items from their collections are by need temporary, disadvantaging those who did not get access their impermanence and curtailing a broader understanding and involvement can become more permanent in their digital capture and online dissemination as an alternative mode to their temporal presence. ${ }^{84}$ The dynamic and emerging state of multi-modal archives is reflected in their evolution across four paradigms from 'juridical legacy to cultural memory to societal engagement to community archiving ${ }^{85}$ with all phases reflected in the fashion archive, the interpretation of critical evidence embedded and embodied in objects and texts from the archive.

This state also validates the existence of special collections, such as fashion archives as active repositories of records and objects, constituting the 'archival nexus' and the incumbent usage, worth and nature embedded in the record-event relationship across time, space and place. The contemporary fashion archive is positioned as a multivocal site for archival interactions with 'the record as object of study'. ${ }^{86}$ The recognition that their use and interpretation are fluid and dynamic yields a range of possible outcomes in making sense of, and giving meaning to past events through records and objects selected, mediated and interpreted by both archivists and users. If these fashion archives 
perform, activate, mediate and store memory through the preservation and dissemination of fashion records to facilitate the authorship of the fashion narrative ${ }^{87}$ for historical, educational, commercial or cultural purposes then we can accord them with agency. This agency potentially enables the activation of memory and plays a vital role, not just in narrating, but also in influencing social, cultural and political processes ${ }^{88}$ in non-Western contexts. In the Hong Kong context, material memory located in archives can be a contentious reminder of a colonial past (which explains their relative absence and lack of development of any narrative), the celebration of a new localism as in the umbrella movement ${ }^{89}$ homage paid to a Hong Kong celebrity or as a way of negotiating constructed identity. The colonial heritage and postcolonial condition appear to have resulted in a deeper search for identity based on the uniqueness of lived experiences, as evidenced in the outputs of Hong Kong popular culture, such as fashion. It can also be interpreted as a site of displacement, reformulation and diminishing of local fashion culture in favour of a dominant, colonised western design framework. ${ }^{90}$ As such, the archive is the repository of the highs and lows of the cultural history of place and space, which the archivist has to manage being ever mindful of local context and the potential resistance, for example, of appropriating heritage sites as an extension of the institution.

Localised, situated perspectives on archives also make clear the need to question and adapt generic archive theories in explaining and managing archives, in emerging knowledge fields such as fashion studies, that are located in diverse cultural spaces and places and represent their inherent historic and post-colonial complexities as exhibited in Hong Kong. Hence, archives can also be a source for readdressing colonial and postcolonial assumptions about historical events and trends. Some scholars consider that colonial powers operating in Asia represented a global cultural hegemony often constituting a one way power flow and embodied type of cultural domination that 
manifested itself in a surface level orientalisation of local cultural forms which were appropriated into local cultural aesthetics, ${ }^{91}$ as with artistic oriental signifiers or the wearing of Japanese kimonos as fashion statements or traveller trophies. This created a cultural space in which local creatives could generate their own popular cultural texts, sometimes influenced by the culture and rituals of the colonisers as with modern hairstyles and modern designer outfits. The role of fashion archives in supporting this intra-cultural exchange thesis and the reformulation of the hegemonic colonial impact on local culture and popular culture are evident in the content of collections. In the case of the current study, the significant inclusion of Western sourced designer outfits, often donated by local celebrities or staff, alongside the work of local designers and traditional Chinese dress such as the qipao supports this notion of fashion as boundary-less.

The sense of the archive operating in isolation from communities and users is invalid for those located in modern urban contexts such as Hong Kong are never far away from commercial considerations. Fashion exhibitions in museums have latterly been criticised for selling their soul to commercial interests by hosting exhibitions of individual designer's work, living or dead. These populist displays have been accused of accepting questionable commercial sponsorship support or focussing on the glamour and glitz of fashion above its more serious aspects. Such public debates evoke the high versus low culture/education versus entertainment dichotomy and the circular argument about fashion's true identity as located in art or commerce. Yet, the usefulness of sourcing monetary support based on exchange value, or in activating knowledge and social capital from other communities of practice is founded on connections that support the existence of archives. Endorsement and support from community stakeholders is particularly significant in post-colonial cultures and societies searching to make sense of their identity and their contested past so that they can forge a more meaningful future. 
The cultural take on archives is also complex and can reflect the selective indifference towards history that some societies exhibit on account of their past often fraught with the politics of disappearance or recalibration. ${ }^{92}$ Equally, in émigré cultures there is a tendency to look forwards rather than backwards. However, this perspective is changing, in part as identities shift and evolve in post-colonial and de-colonial contexts whereby the archive may become a valuable way to explore collective and individual historical journeys which the material culture of fashion enables in both text and object based format, both offline and online, with the latter interface being usefully applied to the increasing 'democratisation' of fashion objects and virtual records and events through interactive digital sites. ${ }^{93}$ Digital technology adds a new dimension to fashion's embodied material forms and again amplifies how fashion archives can function more widely as an interactive site for personal, social and cultural memories.

Finally, the creative specificity of fashion outputs, resulting from design thinking is preserved and enhanced in the archive, which some scholars have considered to be a creative site in their own right in content, purpose and direction 'a place where identities may be formed, technologies of rule perfected, and pasts convincingly revisited... reflects what individuals, institutions, states, and societies imagine themselves to have been, as well as what they may imagine themselves becoming.' 94 This is highly pertinent for Hong Kong as a former textile producer and aspirant fashion capital and creative city where a fashion archive can assist the 'dreams of a small nation in a polycentric world' given the shifting centres and 'traveling discourse' ${ }^{95}$ of new fashion centres from what was once considered to be fashion periphery to fashion centre.

Fashion archives are fulfilling various functions for increasingly wider communities of interests as the ivory tower separatism wanes, 'enabling design-led institutions (who are often characterised as elitist) to engage more closely with the 
public's day-to day experience of designer-led fashion.' ${ }^{96}$ Meanwhile, the role of archivist as content manager, curator, mediator, educator, event organiser, and promoter facilitates this expanded archival brief.

As fashion exhibitions, fashion scholarship and fashion education continue to increase in popularity in the search for embodied meaning, the fashion archive mediates the dualities of evidence and memory; material and virtual content as a much-needed resource representing the storehouse of creative inspiration and design innovation, cultural memory and social significance for a potentially limitless range of users given the fervour of interest that fashion collections and exhibitions now appear to generate in both commercial and educational domains. In the Hong Kong context, this foregrounds issues of postcolonial identity management founded on negotiated interpretations of the story of fashion and what it signified for the producer, worker and user in the past, present and future. The colonial history of fashion in Hong Kong belies a cultural identity crisis manifested in the power relations between creator and political institutions inherent in the management of modernity whereby policy makers dream of economic success and designers dream of their work being recognised on the world stage. The fashion archive in its physical materiality and symbolic representations of memory, preserves and facilitates access to objects and texts that can offer historical validity for the transnational flow of fashionable goods, people, trade and style in modern colonial times and the reimagining of postcolonial, postmodern spaces that are multi-vocal and multiple. Given the significant popular interest in fashion and lifestyle in the public domain archives offer the possibility of enabling a more reflexive and discursive engagement with fashion studies. The presence and evolution of the fashion archive in other places in Asia, such as Hong Kong, once considered peripheral or supplementary to the global fashion system in terms of production, design, education or scholarship, now provide an uncontained, 
dynamic space for negotiating identities and finding agency and inspiration by enabling users to revisit and interpret popular cultural forms exemplified by the dynamics of fashion as material object and multi-modal text as a way of making sense of the lived social experience which is always ongoing and infinite.

\section{Notes}

${ }^{1}$ Steele, "A Museum of Fashion," 327-335.

${ }^{2}$ McNeil, "We're Not in the Fashion Business," 78.

${ }^{3}$ Craik, Fashion: The Key Concepts, 2.

${ }^{4}$ Sapir, Encyclopedia of Social Sciences, 139.

${ }^{5}$ Mauss, "Techniques of the Body," 72-75.

${ }^{6}$ Taylor, The Study of Dress History, 64.

${ }^{7}$ Clark, Spectres: When Fashion Turns Back, 111.

${ }^{8}$ Aspers and Skov, "Encounters in the Global Fashion Business," 810-811.

${ }^{9}$ Steele, "Museum Quality," 7-30.

${ }^{10}$ Breward, "Between the Museum," 86-87.

${ }^{11}$ Nesmith, Tom. "Reopening Archives", 262-263.

12 Millar, Archives: Principles and Practice, 11.

${ }^{13}$ Lepecki, "The Body as Archive", 30.

${ }^{14}$ Munteán et al., Materializing Memory, 4.

${ }^{15}$ Said, Orientalism, 3-6.

${ }^{16}$ Williams, Culture, 96.

${ }^{17}$ Lowenthal, The Heritage Crusade, 202.

${ }^{18}$ Bix, "Equipped for Life", 728-729.

${ }^{19}$ Steele, ibid., 9.

${ }^{20}$ Greenhalgh, "Education, Entertainment and Politics," 86.

${ }^{21}$ Taylor, ibid., 67-69.

${ }^{22}$ Entwistle, The Fashioned Body, 6.

${ }^{23}$ Anderson, "Museums as Fashion Media," 374.

${ }^{24}$ Storey, Cultural Theory and Popular Culture, 6-7.

${ }^{25}$ Steele, "A Museum of Fashion," 327.

${ }^{26}$ Steele, ibid., 333.

${ }^{27}$ Taylor, ibid., 64-65.

${ }^{28}$ Anderson, ibid., 376.

${ }^{29}$ Anderson, ibid., 374.

${ }^{30}$ Taylor, ibid., 83.

${ }^{31}$ Hall, "Memories of style," 157.

${ }^{32}$ Meehan, "The Archival Nexus," 158.

${ }^{33}$ Cook, "Evidence, Memory, Identity and Community," 97.

${ }^{34}$ Schellenberg, "The Appraisal of Modern Records," 5.

${ }^{35}$ Derrida, Archive Fever, 6-9.

${ }^{36}$ Derrida, ibid., 79.

${ }^{37}$ Cook and Schwartz, "Archives, Records, and Power," 185.

${ }^{38}$ Millar, ibid., 3.

${ }^{39}$ Williams, Managing Archives, 4.

${ }^{40}$ Millar, ibid., 11.

${ }^{41}$ Buckley and Clark, Fashion and Everyday Life, 45. 
${ }^{42}$ Burns, "University Creates First Public Menswear Archive".

${ }^{43}$ Hall, ibid., 157.

${ }^{44}$ Steele, "A Museum of Fashion," 14-16.

${ }^{45}$ Lepecki, ibid., 48.

${ }^{46}$ Sabharwal, Digital Curating in the Digital Humanities, 56.

${ }^{47}$ Wenger-Trayner, Communities of Practice, 2-4.

${ }^{48}$ Cook, ibid., 95.

${ }^{49}$ Evans, "Developing the Perfect Fashion Archive," 2.

${ }^{50}$ McRobbie, "Fashion Culture," 63-64.

${ }^{51}$ Evans, ibid., 2.

${ }^{52}$ Skov, "Hong Kong Fashion Designers," 555.

${ }^{53}$ Ling, "From "Made in Hong Kong," 110-112.

${ }^{54}$ Skov, "Seeing is Believing," 191.

${ }^{55} \mathrm{Wu}$, "Hong Kong's Vanishing Archives," 3.

${ }^{56}$ Cook, ibid., 105.

${ }^{57}$ Hong Kong Design Institute, "Fashion Archive Website".

${ }^{58}$ Hong Kong Design Institute, ibid.

${ }^{59}$ Hong Kong Design Institute, $i b i d$.

${ }^{60}$ Meehan, ibid., 129.

${ }^{61}$ Yeo, "Concepts of Record," 316-318.

${ }^{62}$ Lo, "Building a Crowd-Sourced Community Archive," 9.

${ }^{63}$ Abbas, Hong Kong: Culture, 1-3.

${ }^{64}$ Chen and Szeto, "The Forgotten Road," 453.

${ }^{65}$ Create Hong Kong (CreateHK), is a Hong Kong SAR Government department established under the Communications and Technology Branch of the Commerce and Economic Development Bureau (CEDB) in 2009 with a brief to promote and nurture the advancement of the creative industries.

${ }^{66}$ Huppatz, "Designer Nostalgia in Hong Kong." 16-18.

${ }^{67}$ Skov, "Dreams of Small Nations," 152.

${ }^{68}$ Craik, ibid., 8.

${ }^{69}$ Sharp, "Geographies of Postcolonialism," 2.

${ }^{70}$ Skov, ibid., 139-140.

${ }^{71}$ Craik, The Face of Fashion, 26.

${ }^{72}$ Peirson-Smith, "Wishing on a Star," 173-174.

${ }^{73}$ Evans, ibid., 9.

${ }^{74}$ Hall, ibid., 151,

${ }^{75}$ Flinn, "The Impact of Independent and Community Archives," 146-147.

${ }^{76}$ Hong Kong Design Institute, "Celebrating Nearly 150 Years of Denim Culture".

${ }^{77}$ Abbas, ibid., 65.

${ }^{78}$ Adell, et al. Between Imagined Communities, 78-79.

${ }^{79}$ Abbas, ibid., 67.

${ }^{80}$ Abbas, ibid.,143.

${ }^{81}$ Kwint, "Introduction: The Physical Past," 2.

${ }^{82}$ Steele, ibid., 334.

${ }^{83}$ Wilson, Adorned in Dreams, 1.

${ }^{84}$ Palmer, "Permanence and Impermance," 39.

${ }^{85}$ Cook, ibid., 116.

${ }^{86}$ Meehan, ibid., 161.

${ }^{87}$ Peirson-Smith and Hancock, Transglobal Fashion Narratives, 6-7.

${ }^{88}$ Blouin and Rosenberg, Archives, Documentation, and Institutions of Social Memory, 2.

${ }^{89}$ Chen and Szeto, ibid., 436-437.

${ }^{90}$ Sharp, Geographies of Postcolonialism, 114. 
${ }^{91}$ Iwabuchi, Recentering Globalization, 44-46.

${ }^{92}$ Abbas, ibid., 7-8.

${ }^{93}$ Millar, ibid., 59.

${ }^{94}$ Blouin and Rosenberg, ibid., ix.

${ }^{95}$ Skov, ibid., 150.

${ }^{96}$ Anderson, ibid., 388.

\section{Bibliography}

Abbas, Ackbar. Hong Kong: Culture and the politics of disappearance. Hong Kong: Hong Kong University Press, 1997.

Adell, Nicholas, Regina Bendix, Chiara Bortolotto, and Markus Tauschek. Between imagined communities and communities of practice. Göttingen: Universitätsverlag Göttingen, 2015.

Anderson, Fiona. "Museums as Fashion Media," In: Bruzzi, Stella, and Pamela Church Gibson. Fashion Cultures Revisited: Theories, Explorations and Analysis, 371-389. London: Routledge, 2000.

Aspers, Patrik, and Lise Skov. "Encounters in the Global Fashion Business: Afterword." Current Sociology 54, no. 5 (September 2006): 802-13.

doi:10.1177/0011392106066817.

Bastion, Jeanette A., and Ben Alexander. Community Archives: The Shaping of Memory, (Principles and Practice in Records Management and Archives). Cambridge: Facet Publishing, 2009.

Bix, Amy Sue. "Equipped for life: Gendered technical training and consumerism in home economics, 1920-1980." Technology and Culture 43, no. 4 (2002): 728-754. 
Blouin, Francis X., and William G. Rosenberg, eds. Archives, Documentation, and Institutions of Social Memory: Essays from the Sawyer Seminar. Michigan: University of Michigan Press, 2007.

Breward, Christopher. "Between the Museum and the Academy: Fashion research and its Constituencies." Fashion Theory 12, no. 1 (2008): 83-93. doi.org/10.2752/175174108X269568.

Buckley, Cheryl, and Hazel Clark. Fashion and Everyday Life, London and New York: Bloomsbury Publishing, 2017.

Burns, Judith. "University Creates First Public Menswear Archive.” BBC News, 6 September 2017. https://www.bbc.com/news/education-41165926

Chen, Yun-chung, and Mirana M. Szeto. "The Forgotten Road of Progressive Localism: New Preservation Movement in Hong Kong." Inter-Asia Cultural Studies 16, no. 3 (2015): 436-53. doi.org/10.1080/14649373.2015.1071694.

Clark, Judith. Spectres: When Fashion Turns Back. London: V\&A Publications. 2004.

Cook, Terry. "Evidence, Memory, Identity, and Community: Four Shifting Archival Paradigms." Archival Science 13, no. 2 (2013): 95-120. doi.org/10.1007/s10502-0129180-7.

Cook, Terry, and Joan M. Schwartz. “Archives, Records, and Power: from (Postmodern) Theory to (Archival) Performance". Archival Science 2, no. 3-4 (2002): 171-185. doi.org/10.1007/BF02435620.

Craik, Jennifer. The Face of Fashion: Cultural Studies in Fashion. London: Routledge. 2003.

Craik, Jennifer. Fashion: the key concepts. Oxford: Bloomsbury Academic, 2009.

Crooke, Elizabeth. Museums and community: Ideas, Issues and Challenges. Routledge, London, 2007. 
Derrida, Jacques. Archive Fever: A Freudian Impression. Transl. Eric Prenowitz. The Chicago: University of Chicago Press, 1995.

Duranti, Luciana. "The Concept of Appraisal and Archival Theory." The American Archivist 57, no. 2 (1994): 328-44. doi.org/10.17723/aarc.57.2.pu548273j5j1p816.

Entwistle, Joanne. The Fashioned Body: Fashion, Dress and Social Theory. London: John Wiley \& Sons, 2015.

Evans, Claire. “Developing the Perfect Fashion Archive.” In: Fashion Forward. Witney: Interdisciplinary Press, 2011. http://eprints.hud.ac.uk/id/eprint/8346/.

Flinn, Andrew. "Chapter 8: The Impact of Independent and Community Archives on Professional Archival Thinking and Practice." In The Future of Archives and Recordkeeping: A Reader, edited by Jennie Hill, 145-69. London: Facet, 2011.

Greenhalgh, Paul. "Education, Entertainment and Politics: Lessons from the Great International Exhibitions." In The New Museology, edited by Peter Vergo, 74-98. London: Reaktion Books, 1989.

Hall, Suzanna. "Memories of Style: Digitizing the Yorkshire Fashion Archive." Art Libraries Journal 42, no. 3 (2017): 157-61. doi:10.1017/alj.2017.22.

“Hong Kong Design Institute: Fashion Archive Website.” Hong Kong Design Institute, Accessed April 2, 2019, http://www.hkdi.edu.hk/en/knowledge-centre/fashion_archive.php.

“Hong Kong Design Institute: News, “Celebrating nearly 150 years of denim culture.” 1 March 2019, Accessed 20 March, 2019, http://www.hkdi.edu.hk/en/news/publicationdetail.php?product $\mathrm{id}=141$.

Huppatz, Daniel J. "Designer Nostalgia in Hong Kong." Design Issues, 25, no. 2 (2009): 14-28.

Iwabuchi, Koichi. Recentering Globalization: Popular culture and Japanese 
transnationalism. Duke University Press, 2002.

Jenkinson, Hilary. A Manual of Archive Administration: Including the Problems of War Archives and Archive Making. Oxford: Clarendon Press, 1922.

Jimerson, Randall C. "Deciding What to Save, OCLC Systems \& Services. International Digital Library Perspectives 19, no. 4, (2003): 135-140.

Jimerson, Randall C. "Embracing the Power of Archives." The American Archivist 69, no. 1 (2006): 19-32. www.jstor.org/stable/40294309.

Kwint, Marius. "Introduction: the physical past." Material memories: design and evocation (1999): 1-16. In: Kwint, Marius, Christopher Breward, and Jeremy Aynsley, eds. Material Memories. Oxford: Berg, 1999.

Lepecki, André. "The Body as Archive: Will to re-enact and the afterlives of dances." Dance Research Journal 42, no. 2 (2010): 28-48

Ling, Wessie. "From "Made in Hong Kong" to "Designed in Hong Kong": Searching for an Identity in Fashion." Visual Anthropology 24, no. 1-2 (2011): 106-23. https://doi.org/10.1080/08949468.2011.526535.

Lo, Patrick. "Building a Crowd-Sourced Community Archive in Hong Kong: The Challenges and Rewards." Journal of East Asian Libraries 2013, no. 157, (2013): 9. Lowenthal, David. The Heritage Crusade and the Spoils of History. Cambridge: Cambridge University Press, 1998.

Mauss, Marcel. "Techniques of the Body." Economy and Society 2, no. 1 (1973): 70-88. McNeil, Peter. "We're Not in the Fashion Business": Fashion in the Museum and the Academy." Fashion Theory 12, no. 1 (2008): 65-81. doi.org/10.2752/175174108X269559.

McRobbie, Angela. "Fashion Culture: Creative Work, Female Individualization." Feminist Review 71, no. 1 (2002): 52-62. doi.org/10.1057/palgrave.fr.9400034. 
Meehan, Jennifer. "The Archival Nexus: Rethinking the Interplay of Archival Ideas About the Nature, Value and Use of Records," Archival Science, no. 9 (2009): 157164.

Millar, Laura. "On the Crest of a Wave: Transforming the Archival Future." Archives and Manuscripts 45, no. 2 (2017): 59-76. doi.org/10.1080/01576895.2017.1328696.

Millar, Laura. "Touchstones: Considering the Relationship Between Memory and Archives." Archivaria 61, (2006): 105-126.

Millar, Laura. Archives: Principles and Practice. London: Facet Publishing, 2017.

Munteán, László, Liedeke Plate, and Anneke Smelik, eds. Materializing Memory in Art and Popular Culture. New York: Routledge, 2017.

Nesmith, Tom. "Reopening archives: bringing new contextualities into archival theory and practice." Archivaria 60 (2006): 259-274.

Palmer, Alexandra. "Permanence and Impermanence: Curating Western Textiles and Fashion at the Royal Ontario Museum.” In: Vänskä, Annamari, and Hazel Clark, eds. Fashion curating: Critical practice in the museum and beyond. Bloomsbury Publishing, 2017: 39-56.

Peirson-Smith, Anne. "Wishing on a Star: Promoting and Personifying Designer Collections and Fashion Brands." Fashion Practice 5, no. 2 (2013): 171-201. doi.org/10.2752/175693813X13705243201450.

Peirson-Smith, Anne, and Joseph H. Hancock II, Transglobal Fashion Narratives: Clothing Communication, Style Statements and Brand Storytelling. Bristol: Intellect Books Ltd, 2018.

Sabharwal, Arjun. Digital curation in the digital humanities: Preserving and promoting archival and special collections. Waltham, MA: Chandos Publishing, 2015. 
Sapir, Edward. "Fashion. Encyclopaedia of Social Sciences." New York:

Macmillan, Volume 6 (1937): 137-146.

Schellenberg, Theodore R. "The Appraisal of Modern Records." National Archives and Records Administration, 1999, Accessed on January 31, 2019.

https://www.archives.gov/research/alic/reference/archives-resources/appraisalevidential-values.html

Sharp, Joanne. Geographies of Postcolonialism: spaces of power and representation.

London: Sage, 2008.

Skov, Lise. "Hong Kong Fashion Designers as Cultural Intermediaries: Out of Global Garment Production." Cultural Studies 16, no. 4 (2002): 553-569.

Skov, Lise. "Dreams of Small Nations in a Polycentric Fashion World", Fashion Theory 15, no. 2, (2011): 137-156.

Skov, Lise. "Seeing is Believing:" World Fashion and The Hong Kong Young Designers'

Contest." Fashion Theory 8, no. 2, (2004): 165-193.

Steele, Valerie. "A Museum of Fashion is More than a Clothes-bag." Fashion Theory 2, no. 4 (1998): 327-335.

Steele, Valerie. "Museum Quality: The Rise of the Fashion Exhibition.” Fashion Theory 12, no. 1 (2008): 7-30.

Storey, John. Cultural Theory and Popular Culture, London: Pearson Longman, 2009.

Taylor, Lou. The Study of Dress History, Manchester: Manchester University Press. 2002.

Thurston, Anne, and Piers Cain. "The Management of Public Sector Records Project: Managing the records lifecycle." Information Development 11, no. 4, (1995): 198205. 
Wenger-Trayner, Etienne. Communities of Practice: Learning, Meaning, and Identity. Cambridge: Cambridge University Press, 1998.

Williams, Caroline. Managing Archives: Foundations, Principles and Practice. Oxford: Chandos Publishing, 2006.

Williams, Raymond, Culture, London: Fontana. 1981.

Wilson, Elizabeth. Adorned in Dreams: Fashion and Modernity. London: IB Tauris, 2003.

Wu, Venus, "Hong Kong's Vanishing Archives and the Battle to Preserve History” Reuters World News, September 6, 2017. Accessed November 2, 2019. https://www.reuters.com/article/us-hongkong-anniversary-archives/hong-kongsvanishing-archives-and-the-battle-to-preserve-history-idUSKCN1BH0OY.

Yeo, Geoffrey. "Concepts of Record (1): Evidence, Information, and Persistent Representations." The American Archivist, 70, no. 2, (2007): 315-343.

\section{Captions for figures}

Figure 1: Entrance to Fashion Archive at HKDI with video wall. 2019. Photograph by author.

Figure 2: Inside the storage racks of the Fashion Archive HKDI. 2019. Photograph by author.

Figure 3: Interactive archive wall Fashion Archive, HKDA. 2019. Photograph by author. Figure 4: Seminar space inside the Fashion Archive HKDI. 2019. Photograph by author. Figure 5: King of Fashion: Denim Exhibition mixed materials display, Fashion Archive HKDI. March 2019. Photograph by author.

Figure 6: King of Fashion: Denim Exhibition, Jean Paul Gautier denim jacket, Fashion Archive HKDI. March 2019. Photograph by author. 
